\title{
Contribution of the deflection of tapered roller bearings to the misalignment of the pinion in a pinion-rack transmission
}

\author{
V. Roda-Casanova ${ }^{\mathrm{a}, *}$, F. Sanchez-Marin ${ }^{\mathrm{a}}$ \\ ${ }^{a}$ Department of Mechanical Engineering and Construction, Universitat Jaume I, \\ Castellon, Spain
}

\begin{abstract}
The misalignment of the gears is one of the main causes of premature failure in gear transmissions. This misalignment can be caused by different phenomena where the deformation of the elastic elements of the transmission usually has a major importance. In this paper, a pinion and rack transmission is used to investigate the misalignment of the pinion produced by the deflection of both shaft and bearings, focusing in the contribution of the bearings to this misalignment. For this task, a design space with 261 different cases of pinion and rack transmission has been explored. For each case, a realistic 3D FEM model (including gears, shaft and roller bearings) has been created and the coupled structural and contact problem has been solved. From the results of the FEM models, the different parameters of misalignment of the pinion have been computed and analyzed through five studies. These studies revealed the high importance of the elasticity of the bearings in the misalignment of the pinion and, in general, the important error that can be assumed when the bearings are not included in the structural models of gear transmissions.
\end{abstract}

Keywords: Pinion and rack, Roller bearings, Gear misalignment, Shaft deflection

\footnotetext{
*Corresponding author

Email address: vroda@uji.es (V. Roda-Casanova)
} 


\section{Introduction}

The calculation of the load capacity is an important step in the design process of a gear drive. Its main purpose is to determine whether the new design will be able to transmit the power for which it is designed, without leading to a premature failure of any element of the transmission. While there are several methods to determine the load capacity of a gear transmission, the most common are those included in ISO6336 [1] and AGMA2001-D04 [2] standards, where the maximum values of contact and bending stresses at the gear teeth are compared to the allowable stress values.

Among the physical phenomena that may affect the load capacity of a given design of a gear transmission, one of the most relevant is the misalignment of the gears. When two gears are misaligned, they do not mesh properly and a defective contact pattern is produced, leading to uneven load distributions along the face width of the gear teeth. These uneven load distributions may result in bending and contact stresses exceeding the permissible values, that can cause premature fatigue failures. Several investigations can be found in the literature showing the relation between gear misalignment with uneven load distributions $[3,4]$, with the increase of bending stresses $[5,6]$ and with the increase of contact stresses $[6,7,8,9]$.

However, the negative consequences of the misalignment of the gears are not limited to reducing its load carrying capacity. It has been shown that they also favor the occurrence of other adverse effects, such as an increase of wear in the contact surfaces $[10,11,12,13]$, an increase of heat generation [10] and the introduction of transmission errors, vibration and noise $[14,15,16]$.

According to Houser [17], the main causes that produce the misalignment of gears are the manufacturing and assembly errors, the distortions produced by thermal and centrifugal effects, and the elastic deflections of the elements

of the transmission under load. Among these causes, this work is focused in the gear misalignments produced by the elastic deflections under load. The AGMA2001-D04 Standard [2] classifies these deflections into four categories:

- Elastic deflections of pinion and gear teeth.

- Elastic deflections of pinion and gear bodies.

- Elastic deflections of shafts, bearings, cases and foundations that support the gears. 
- Displacements of the pinion and gear due to clearances in bearings and splines.

When experimental analyses are carried out using gear test rigs, it is possible to take into account all the possible elastic deflections in the transmission [3, 5, 18]. But experimental tests are expensive and difficult to extend to a wide collection of cases. For these reasons, important efforts in the development of analytical and numerical models have been continuously performed. The most relevant analytical methods to determine the misalignment of gears could be those included in ISO6336 [1] and AGMA2001-D04 [2] standards, that have been extended by Koide [19]. All these models allow for the consideration of the elastic deflection of the shaft, but no all of them are able to take into account the elastic deflections of the bearings.

However, with the increase of the computation capabilities of modern computers, the finite element analysis of the transmission is getting a major role when studying the misalignment of gears. But the finite element models used in previous works have unequally taken into account the deflection of the several elastic element in the transmission. In some finite element models $[20,18,9]$, only the elastic deflections of the gear teeth are considered, produced by the bending and contact deformation. In many other cases, the finite element models of the transmission are extended to include the elastic deflections of the gear bodies $[6,11,15]$. In all these cases, an arbitrary misalignment is preimposed to the gears when configuring the finite element model. Recently, the authors have proposed finite element models [4] where the deflection of the shafts can be taken into account in the analyses. However, no previous works have been found where the elastic behavior of the bearings is included in the finite element models of gear transmissions.

In this work, a three-dimensional finite element model of a gear transmission is proposed, allowing to take into account the elastic behavior of gears, shafts and bearings when studying the gear misalignment. The main purpose of this model is to quantify the contribution of the elastic deflections of the bearings to the gear misalignment of realistic gear drive designs. For this task, a pinion and rack transmission has been selected for the following reasons:

- The pinion and rack transmission is simple. It has a rack and just one shaft with a unique gear (the pinion), so the interpretation of misalignment due to the deflection of the elements is easier than when there are several shafts with more than one gear on each shaft. 
- The simplicity of the transmission reduces the number of variables of study, allowing to analyze a higher number of values for each variable.

- The finite element models of the transmission are smaller (in terms of number of nodes and elements) than in other transmissions. This makes possible to create realistic models with finer meshes that will provide more accurate results.

Using this type of transmission, the influence of the bearing deflection in the gear misalignment has been studied by analyzing 261 finite element models of pinion and rack transmissions. The conclusions drawn from this study can be applied to realistic designs of gear transmissions within the specified design ranges, and some conclusions can be extrapolated to general gear design cases.

\section{Description of the physical model}

This study has been performed considering a generic pinion and rack transmission (figure 1), composed by a spur pinion grounded on a shaft, a rack and a pair of tapered roller bearings arranged face-to-face. The set of parameters that define the transmission is shown in table 1 . Some of these parameters have not varied in the study, while others have been considered design variables. All design parameters have been set with realistic values according to commercial designs of this type of transmissions for the selected nominal torque.

Regarding the gears, both pinion and rack have standard involute geometries and the transmission is assumed to be completely free of manufacturing and assembly errors. The pinion is grounded on a shaft that has shoulders in both ends to axially support the roller bearings. The diameter of the shaft $\left(d_{s h}\right)$ and the position that the pinion occupies over the shaft $\left(z_{g}\right)$ are both considered design variables in this study.

The shaft is supported by two identical tapered roller bearings, referred to as bearing $B_{A}$ and bearing $B_{B}$. The main parameters of the bearings have been chosen from commercial models (series 30302, corresponding to ISO 355 [21]), according to the load they have to support and a standard expected life, and they are shown in table 2 following the nomenclature used by Harris [22]. 


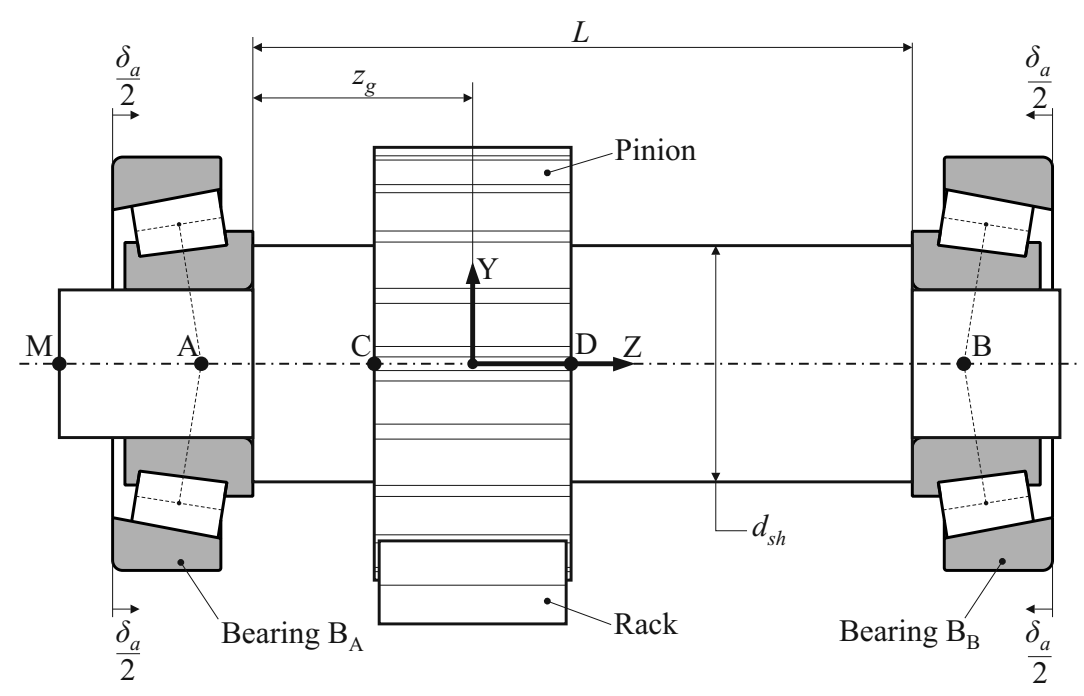

Figure 1: Design details of the pinion shaft

Table 1: Design data of the pinion and rack transmission

\begin{tabular}{lcc}
\hline Parameter & Type & Nominal value \\
\hline Normal module, $m_{n}$ & Fixed value & $2 \mathrm{~mm}$ \\
Pressure angle, $\alpha$ & Fixed value & $20^{\circ}$ \\
Tooth number of the pinion, $z_{P}$ & Fixed value & 20 \\
Face width of the pinion, $b_{P}$ & Fixed value & $20 \mathrm{~mm}$ \\
Face width of the rack, $b_{G}$ & Fixed value & $19 \mathrm{~mm}$ \\
Bearing span, $L$ & Fixed value & $67 \mathrm{~mm}$ \\
Material, Young's modulus, $E$ & Fixed value & $210 \mathrm{GPa}$ \\
Material, Poisson's ratio, $\nu$ & Fixed value & 0.3 \\
Shaft diameter, $d_{s h}$ & Design variable & $24 \mathrm{~mm}$ \\
Pinion position, $z_{g}$ & Design variable & $0.5 \mathrm{~L}$ \\
Applied torque, $T$ & Design variable & $75 \mathrm{Nm}$ \\
Bearing axial interference, $\delta_{a}$ & Design variable & $0 \mu \mathrm{m}$ \\
\hline
\end{tabular}


Table 2: Design data of the tapered roller bearings

\begin{tabular}{lc}
\hline Magnitudes & Values \\
\hline Cone width & $13 \mathrm{~mm}$ \\
Cone bore diameter & $15 \mathrm{~mm}$ \\
Cone-included angle & $14.67^{\circ}$ \\
Distance from the pitch cone apex to the cone front face & $83.22 \mathrm{~mm}$ \\
Cup width & $11 \mathrm{~mm}$ \\
Cup outside diameter & $42 \mathrm{~mm}$ \\
Cup-included angle & $21.60^{\circ}$ \\
Distance from the pitch cone apex to the cup back face & $81.97 \mathrm{~mm}$ \\
Distance from the cone back face to the effective center location & $4.6 \mathrm{~mm}$ \\
Roller-included angle & $3.465^{\circ}$ \\
Roller end-to-end length & $8.93 \mathrm{~mm}$ \\
Small-end diameter of the roller & $5.16 \mathrm{~mm}$ \\
Number of tapered rollers & 12 \\
\hline
\end{tabular}

The bearing arrangement allows the introduction of an axial displacement to the cup of both bearings $B_{A}$ and $B_{B}$, to achieve an end-play (axial clearance) or an axial preload of the system. The axial displacement is measured as the increment of the distance between the cups of the bearings, taking as a reference the position where a theoretical unloaded contact between cup, rollers and cone is produced. It is positive when the distance between the bearing cups is reduced (inducing a preload of the system), and negative when the distance between the bearing cups is increased (producing a clearance between rollers and races).

The global Cartesian coordinate system of the model is defined with origin in the center of the pinion. The $Z$ axis is parallel to the longitudinal axis of the shaft, and the $Y$ axis is perpendicular to the pitch plane (figure 2a).

A set of keypoints is defined in the transmission, placed over the longitudinal axis of the shaft (figure 1). Keypoints $A$ and $B$ are coincident with the location of the effective center location of bearings $B_{A}$ and $B_{B}$, respectively. Keypoints $C$ and $D$ are placed in the intersection of the endplanes of the pinion with the longitudinal axis of the shaft. Keypoint $O$ is placed at the midpoint of the segment $\overline{C D}$, that coincides with the origin of the global coordinate system. Finally, keypoint $M$ is placed at the intersection of the longitudinal axis of the shaft and its endplane, where the torque $(T)$ 
is applied.

\section{Parametrization of the misalignment of the pinion}

In a pinion and rack transmission, the power is usually transmitted from the pinion to the rack through the contact between their teeth. As a consequence of this contact, a pressure distribution is generated within the contact areas of the teeth, producing the deflection of the elastic elements of the transmission and causing the misalignment of pinion respect to the rack. The study of this misalignment is one of the main objectives of this investigation.

The misalignment of the pinion respect to the rack can be parametrized by three translations and two rotations of the pinion (the misalignment associated to the third rotation refers to the transmission error). In this work, these parameters have been measured according to the notation proposed by Houser [17], that is based in the plane of action instead of the pitch plane (figure 2a). In this proposal the misalignment of the pinion is divided intro three categories:

a) Angular misalignment in the plane of action $\left(\theta_{\pi}\right)$.

b) Angular misalignment in a plane perpendicular to the plane of action $\left(\theta_{\gamma}\right)$

c) Parallel misalignment (change of center distance)

The parallel misalignment is divided into two components, since they may have different repercussions on the transmission:

c.1) Transversal displacement of the pinion $\left(\delta_{X Y}\right)$.

c.2) Axial displacement of the pinion $\left(\delta_{Z}\right)$.

This work is focused on the misalignment of the pinion due to the deformation of bearings and shaft (and not due to the deformation of the pinion and rack themselves). In consequence, the misalignment magnitudes are determined from the position that the keypoints $C, D$ and $O$ occupy when the shaft is deformed due to the torque (denoted by $C^{\prime}, D^{\prime}$ and $O^{\prime}$ respectively, as shown in figure $2 \mathrm{~b}$ ). To ease the measurement of the misalignment of the pinion, a local Cartesian coordinate system is defined with the same origin as the global coordinate system. The $Z_{L}$ axis is parallel to the global $Z$ axis 


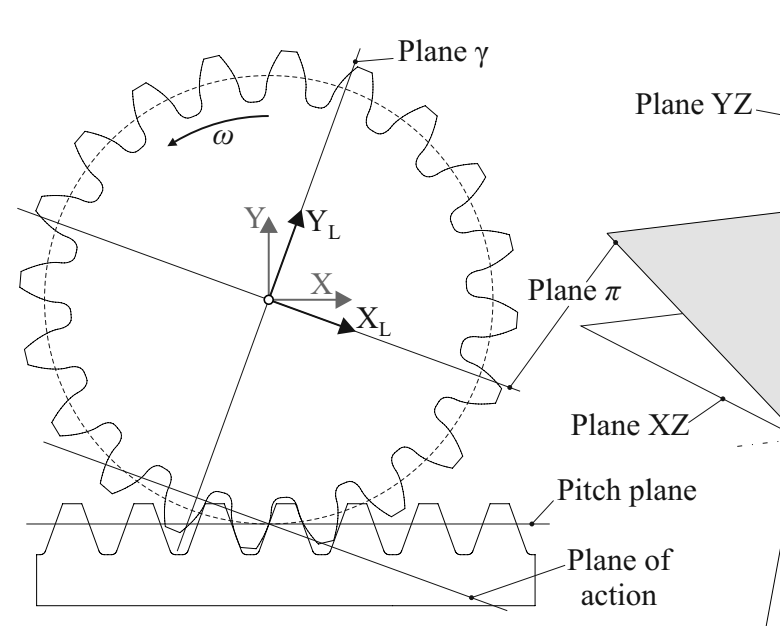

(a)

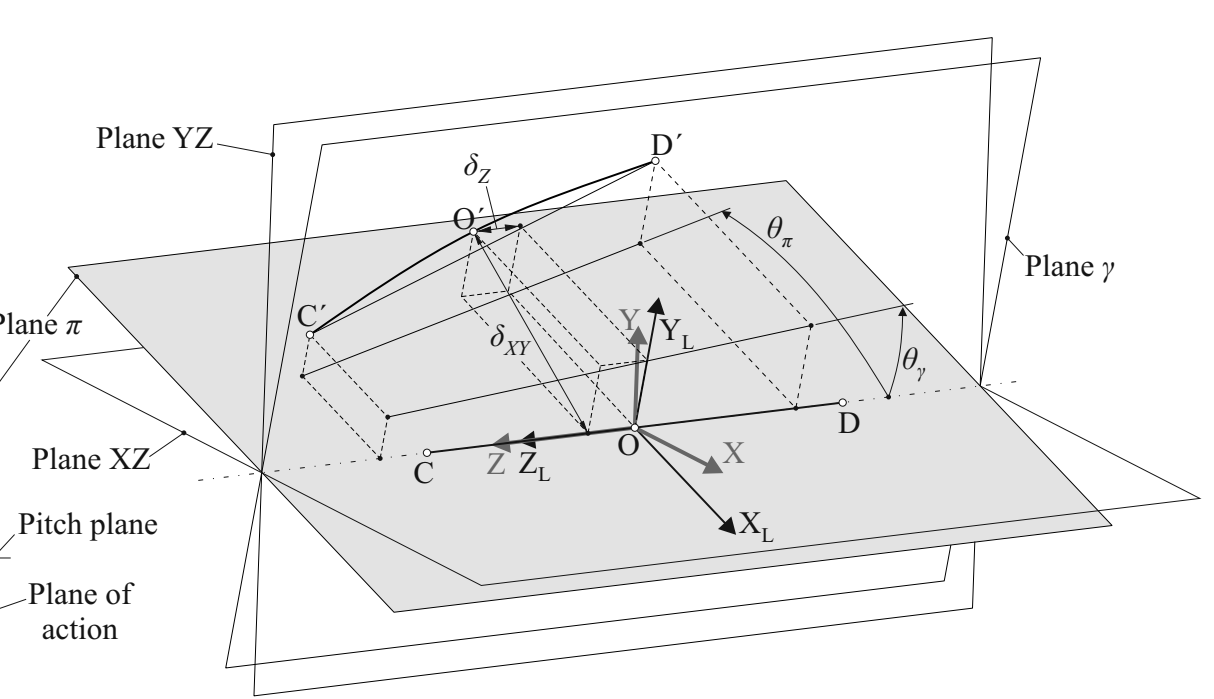

(b)

Figure 2: Description of the misalignment of the pinion

and the $X_{L}$ axis is parallel to the plane of action, as shown in figure 2a. The local axes $X_{L}$ and $Z_{L}$ define the plane $\pi$, that is parallel to the plane of action. The local axes $Y_{L}$ and $Z_{L}$ define the plane $\gamma$, that is perpendicular to the plane of action.

The angular misalignment in the plane of action $\left(\theta_{\pi}\right)$ is defined as the signed angle between the segment $\overline{C D}$ and the orthogonal projection of the segment $\overline{C^{\prime} D^{\prime}}$ onto plane $\pi$. This angle is considered positive when the misalignment is produced in the positive direction of axis $Y_{L}$. On the other hand, the angular misalignment in the plane $\gamma\left(\theta_{\gamma}\right)$ is defined as the signed angle between the segment $\overline{C D}$ and the orthogonal projection of the segment $\overline{C^{\prime} D^{\prime}}$ onto plane $\gamma$. This angle is considered positive when the misalignment is produced in the positive direction of axis $X_{L}$.

The position of the displaced point $O^{\prime}$ is defined by the vector $\mathbf{r}_{O^{\prime}}$. The transversal displacement of the pinion $\left(\delta_{X Y}\right)$ is defined as the magnitude of the orthogonal projection of the vector $\mathbf{r}_{O^{\prime}}$ onto a plane parallel to plane $X Y$. Finally, the axial displacement of the pinion $\left(\delta_{Z}\right)$ is defined as the magnitude of the projection of the vector $\mathbf{r}_{O^{\prime}}$ onto $Z$ axis.

As mentioned before, the misalignment considered in this study is produced by two different contributions: the elastic deflection of the shaft and the elastic deflection of the bearings. This fact is illustrated in figure 3 for 
the angular misalignment in the plane of action (figure $3 \mathrm{a}$ ), the angular misalignment in a plane perpendicular to the plane of action (figure 3b), the transversal displacement of the pinion (figure 3c), and for the axial displacement of the pinion (figure $3 \mathrm{~d}$ ).

Any angular misalignment of the pinion $\left(\theta_{\pi}\right.$ or $\left.\theta_{\gamma}\right)$ can be considered as the sum of two theoretical angles (figure $3 \mathrm{a}$ and $3 \mathrm{~b}$ ):

$$
\begin{aligned}
& \theta_{\pi}=\theta_{\pi b}+\theta_{\pi s} \\
& \theta_{\gamma}=\theta_{\gamma b}+\theta_{\gamma s}
\end{aligned}
$$

where:

- $\theta_{\pi b}$ and $\theta_{\gamma b}$ are the angular misalignments produced by the elastic deflection of the roller bearings in plane $\pi$ and plane $\gamma$, respectively, and

- $\theta_{\pi s}$ and $\theta_{\gamma s}$ are the angular misalignments produced by the elastic deflection of the shaft in plane $\pi$ and plane $\gamma$, respectively.

The angles $\theta_{\pi b}$ and $\theta_{\gamma b}$ are not zero when a different deflection is produced at bearings $B_{A}$ and $B_{B}$, and their value can be determined comparing the undeformed and the deformed positions of keypoints $A$ and $B$. In a similar way, the total angular misalignments $\left(\theta_{\pi}\right.$ and $\left.\theta_{\gamma}\right)$ can be computed by comparing the undeformed and deformed positions of keypoints $\mathrm{C}$ and D. Finally, $\theta_{\pi s}$ and $\theta_{\gamma s}$ can be computed using equations $1 \mathrm{a}$ and $1 \mathrm{~b}$, respectively.

A similar reasoning can be applied for the transversal $\left(\delta_{X Y}\right)$ and axial $\left(\delta_{Z}\right)$ displacements of the pinion (figure $3 \mathrm{c}$ and $3 \mathrm{~d}$ ):

$$
\begin{aligned}
& \delta_{X Y}=\delta_{X Y b}+\delta_{X Y s} \\
& \delta_{Z}=\delta_{Z b}+\delta_{Z s}
\end{aligned}
$$

where:

- $\delta_{X Y b}$ and $\delta_{Z b}$ are the displacements of the pinion produced by the elastic deflection of the roller bearings and,

- $\delta_{X Y s}$ and $\delta_{Z s}$ are the displacements of the pinion produced by the elastic deflection of the shaft. 


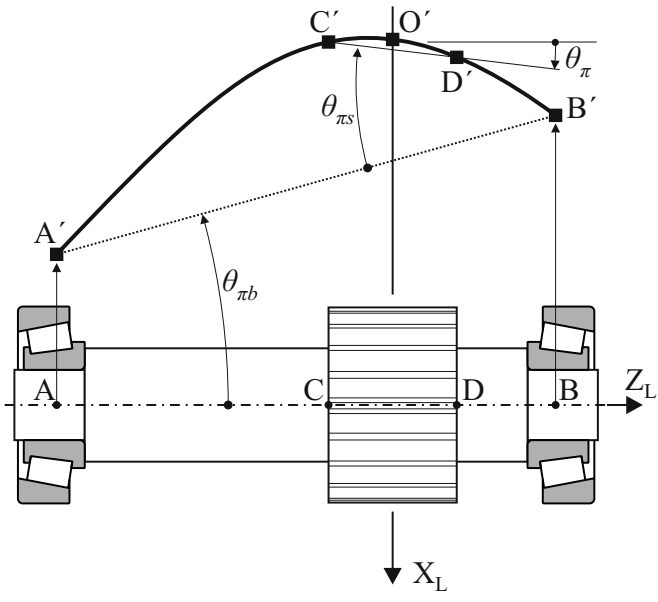

(a)

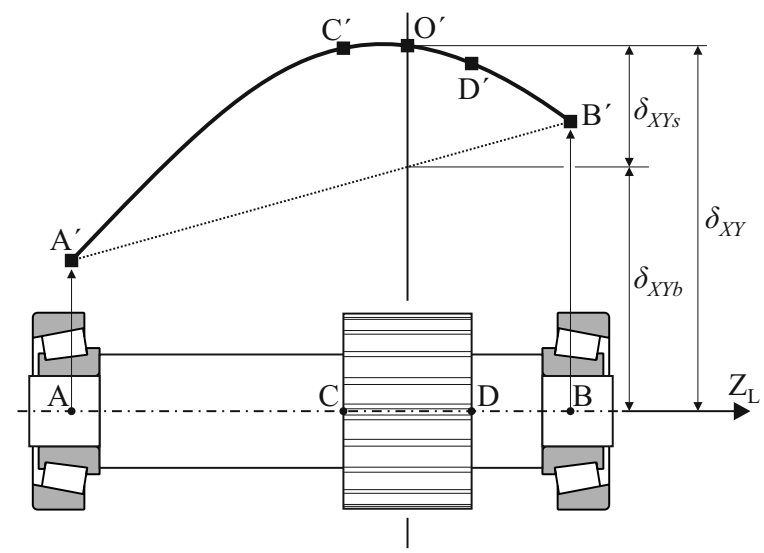

(c)

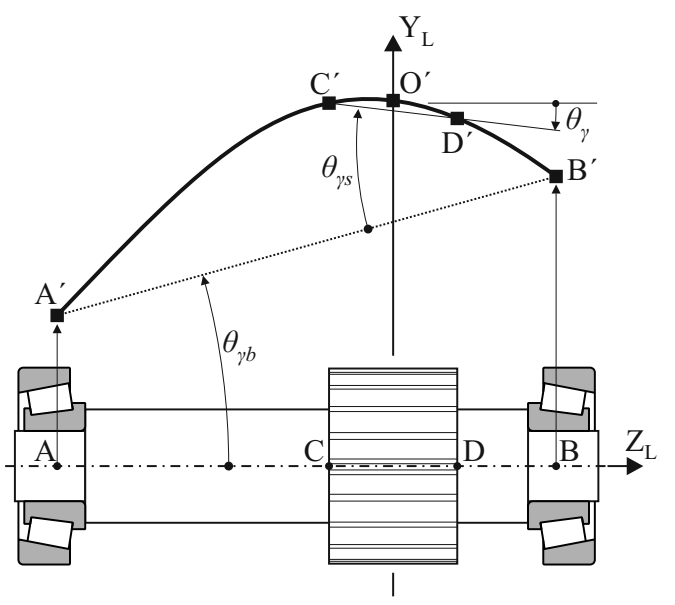

(b)

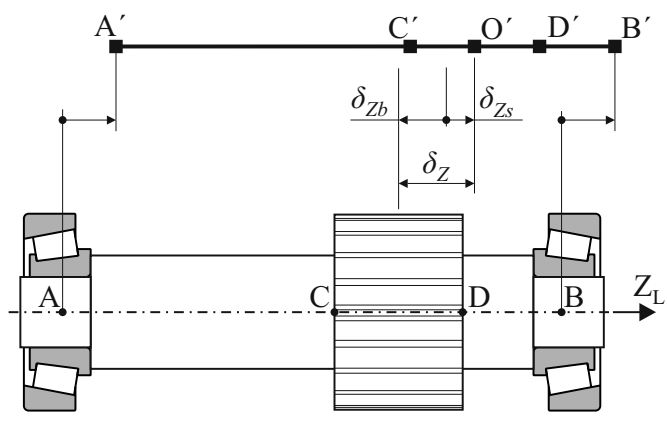

(d)

Figure 3: Sketch of the shaft deflection and definition of angular misalignment in the plane of action (a), angular misalignment in a plane perpendicular to the plane of action (b), transversal displacement of the pinion (c), and axial displacement of the pinion (d). 

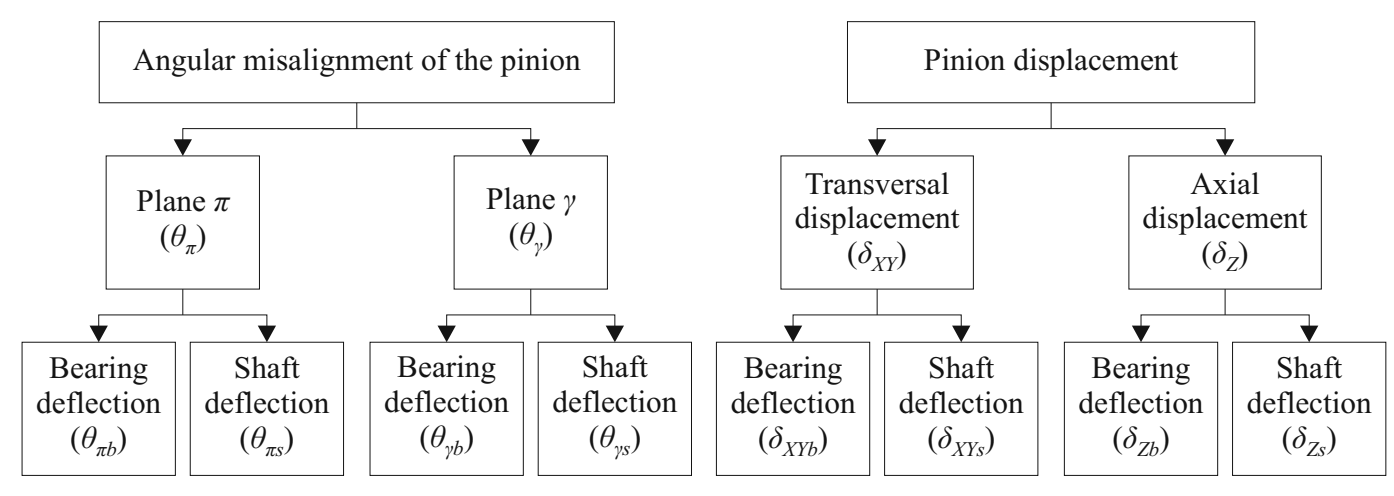

Figure 4: Summary of misalignments

The values of the transversal and axial displacement of the pinion due to the elastic deflection of bearings and shaft can be computed in a way similar to the one described for the angular misalignment. The main difference with the angular parameters is that the displacements due to deformations in shaft and roller bearings always sum, so they never compensate each other.

The parameters of misalignment taken into account are summarized in figure 4. It is important to remark that the misalignment due to deformations in roller bearings and the misalignment due to the deformation of the shaft are not independent, because the two phenomena are coupled in certain degree. But the studies demonstrated that this dependency is low for commercial transmissions (in which both stiffness of shaft and bearings are relatively high) and the analysis of these variables will provide information about the relative importance of the two phenomena in the total misalignment of the pinion.

\section{Description of the finite element model}

In this study, a static analysis of a three-dimensional finite element model of the pinion and rack transmission shown in figure 1 has been used to determine the magnitudes of the misalignment of the pinion under load.

A different finite element model has been developed for each case of study, similar to the one shown in figure 5. In these models, the ground pinion shaft and the rack have been meshed using eight node hexaedral elements with incompatible modes [23]. The computational algorithm proposed by Argyris [20] has been used to build a structured mesh for the teeth of the pinion and rack. This method provides a high degree of accuracy in the 


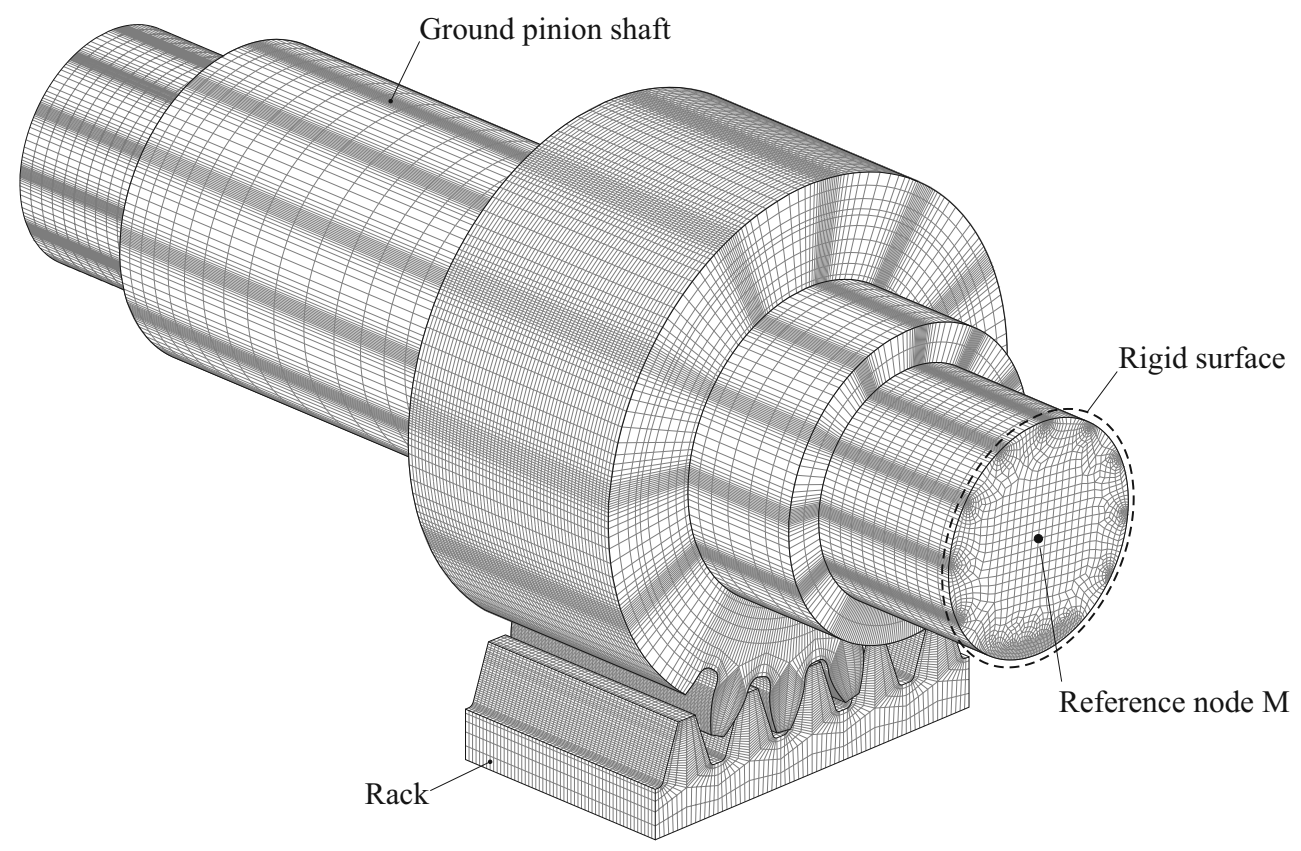

Figure 5: Finite element model of the pinion and rack transmission

definition of the contact surfaces of the pinion teeth, since the position of their nodes is determined analytically using the gearing equation.

To reduce the size of the FEM model and the computational cost, only three teeth have been considered for the pinion. The rest of the geometry has been approached to a cylinder, whose cross section has a second moment of area equal to the one of the real geometry of the pinion, and then meshed together with the shaft using a generic algorithm. A set of reference nodes ( A, B, C, D and M) has been defined in the finite element model, whose position is coincident with the keypoints shown in figure 1.

A linear elastic and isotropic material, whose properties are specified in table 1, has been defined for all finite elements of the model, since the applied loads are assumed to be small and no plastic deformations are considered.

Surface-to-surface, finite sliding, frictionless contacts have been considered between the pinion and rack teeth. A rigid surface has been defined at the free end of the shaft (figure 5), whose movements are coupled to the movements of the reference node $\mathrm{M}$, where the torque is applied. The movement of the transmission is restricted by constraining all degrees of freedom of the nodes corresponding to the base of the rack. 
Table 3: Boundary conditions in keynodes A and B

\begin{tabular}{ccccc}
\hline \multirow{2}{*}{$\begin{array}{c}\text { Support } \\
\text { conditions }\end{array}$} & \multicolumn{2}{c}{ Deference node A } & \multicolumn{2}{c}{ Reference node B } \\
& Displacements & Rotations & Displacements & Rotations \\
\hline SS & All restricted & All allowed & Only allowed in Z & All allowed \\
FS & All restricted & Only allowed in Z & Only allowed in Z & Only allowed in Z \\
\hline
\end{tabular}

The developed finite element model has been finished with three different support conditions for the pinion shaft: simply supported shaft (SS), fully supported shaft (FS) and shaft supported by tapered roller bearings (BS).

The first two cases (SS and FS) represent a common practice in previous works $[4,24,19]$, in which the elastic behavior of the bearings is not considered in the analyses. In these cases, two rigid surfaces have been defined to tie all the nodes of the cross sections of the shaft at keypoints A and B to the reference nodes coincident with these points. The boundary conditions applied to these reference nodes to achieve the aforementioned conditions are described in table 3.

In the third case (BS), the elastic behavior of the bearings is considered by including the tapered roller bearings in the finite element model of the transmission. The cones of the bearings are meshed together with the ground pinion shaft, assuming that there is not relative movement between them, so both cones and the shaft are part of the same volume. To lower the number of degrees of freedom in the finite element model, the geometries of the bearings have been simplified, as shown in figure 6 , removing the cage and the ribs of the bearing cone.

As a result of these simplifications, the rollers have extra degrees of freedom that need to be constrained for the static analysis to converge. Two operations have been required to impose movement constrains to the rollers. In first place, the definition of a local inertial Cartesian coordinate system for each roller of the bearings. The origin of the system is located at the center of the roller, the $Z_{R}$ local axis is parallel to the axis of rotation of the roller and the $Y_{R}$ local axis coincides with the radial direction of the bearing, as shown in figure 6 . And, in second place, the definition of a rigid cylindrical surface of small diameter in the core of each roller, with its movements related to the local coordinate system. Then, the movements of each roller of the bearing can be controlled by applying movement constrains to the rigid surface. The presence of this rigid surface does not have any repercussion on 


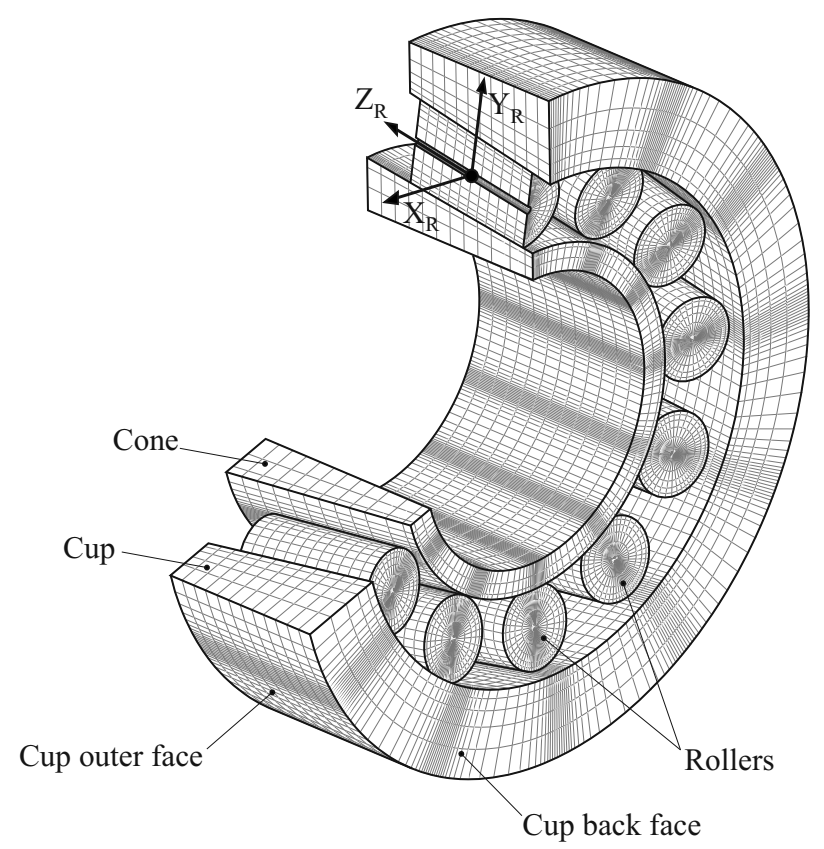

Figure 6: Finite element model of the bearing

the global deflection of the bearing.

Using this strategy, the displacement of the rollers in $Z_{R}$ direction is constrained to take into account the movement restrictions imposed by the missing cone ribs. The displacement of the rollers in $X_{R}$ direction and their rotation around $Y_{R}$ axis are restricted to simulate the effect of the cage. In last place, under the assumption of a static analysis and in order to improve the convergence of the model, the rotation of the rollers around the $Z_{R}$ axis is constrained.

The nodes belonging to the bearing cup outer face have their displacements in the radial direction restricted, simulating that the movement of the bearing is radially restricted by the case. The nodes belonging to the bearing cup back face have prescribed displacements in the longitudinal direction of the shaft ( $\mathrm{Z}$ axis). The magnitude of these prescribed displacements is zero in the reference position, when no axial interference is considered. On the other hand, when the consideration of the axial interference is desired, an axial displacement equal to half the magnitude of the axial interference is prescribed to the nodes of the cup back faces of bearings $B_{A}$ and $B_{B}$.

Surface-to-surface, finite sliding, frictionless contacts are considered be- 
tween the rollers and the cone and cup races. In these cases, the contact formulation is enhanced by approaching the contact areas to second order surfaces, taking advantage of the axysimmetry of the geometries involved in the contact [25]. This enhanced contact formulation, combined with the fact that a finer mesh has been specified for the regions where the contact between the rollers and races is expected (figure 6), increases significantly the accuracy of the calculated contact deformation, contact area and contact pressure distribution.

Under the considered conditions, the resulting finite element model has some limitations that must be pointed out. On one hand, dynamic effects are neglected as a consequence of the static analysis. On the other hand, all the contacts are assumed to be frictionless and free of lubrication, so friction and tribology effects are not considered in the analysis. However, Guo [26] showed that these effects have a minor impact on the bearing deflections when bearings are assumed to operate at moderate speeds and no plastic deformations are taken into account.

\section{Cases of study}

A case of study is defined by assigning a value to each one of the design variables shown in table 1, plus specifying the type of supports considered for the shaft (BS, SS, FS) in the finite element model of the transmission. When several values are assigned to one or more design variables, or several types of supports are considered, the group of cases of study resulting from all possible combinations constitutes a set of cases of study.

In this work, the following studies have been performed by using two sets of cases of study:

- Study of the influence of the applied torque on the misalignment of the pinion: based on set of cases A.

- Study of the influence of the pinion shaft diameter and pinion mounting position on the misalignment of the pinion: based on set of cases A.

- Study of the contribution of the deflection of the bearings to the misalignment of the pinion: based on set of cases A.

- Study of the linearity of the problem of computing the transversal displacement of the pinion: based on set of cases A. 
Table 4: Design variables for the set of cases A

\begin{tabular}{ccc}
\hline Magnitude & Number of values & Values \\
\hline Shaft diameter, $d_{s h}(\mathrm{~mm})$ & 3 & $20,24,28$ \\
Pinion position, $z_{g} / L$ & 7 & $0.2,0.3,0.4,0.5,0.6,0.7,0.8$ \\
Applied torque, $T(\mathrm{Nm})$ & 3 & $50,75,100$ \\
Axial interference, $\delta_{a}(\mu \mathrm{m})$ & 1 & 0 \\
Type of shaft supports & 3 & BS, SS, FS \\
\hline Total number of cases & 189 & \\
\hline
\end{tabular}

- Study of the influence of the axial interference on the misalignment of the pinion: based on set of cases B.

The set of cases $\mathrm{A}$ is defined by the values shown in table 4 . In this set, the stiffness of the shaft has been varied by specifying three different values of shaft diameter. Seven mounting positions of the pinion over the shaft have been considered, covering a wide range designs possibilities. Three different magnitudes of torque have been considered in the study, that are in the range of values used in commercial transmissions of similar module. All three different shaft supporting conditions have been taken into account: simply supported, fully supported and roller bearing supported shaft. And, finally, no axial interference has been specified in this set. As a result of the combination of the values, 189 different cases of study have been analyzed.

The fifth study, in which the influence of the axial interference over the misalignment of the pinion is investigated, is performed using the set of cases B, whose defining values are shown in table 5. In this study, only the bearing support makes sense, so other types of support are not considered. Two values have been used for the mounting position of the pinion, $0.7 \mathrm{~L}$ that produces a high angular misalignment and $0.5 \mathrm{~L}$ that produces a high transversal displacement. The same values as in the set A have been specified for the pinion shaft diameter and for the applied torque. And five different magnitudes of axial interference have been considered, varying from a slight end-play to a high preload. Taking into account all possible combinations of values, this set includes 90 cases of study.

The ranges of the design variables in both set of cases define the scope of this work. These ranges have been selected from commercial designs of this type of transmissions (for similar modules). Obviously, the conclusions 
Table 5: Design variables for the set of cases B

\begin{tabular}{ccc}
\hline Magnitude & Number of values & Value \\
\hline Shaft diameter, $d_{s h}(\mathrm{~mm})$ & 3 & $20,24,28$ \\
Pinion position, $z_{g} / L$ & 2 & $0.5,0.7$ \\
Applied torque, $T(\mathrm{Nm})$ & 3 & $50,75,100$ \\
Axial interference, $\delta_{a}(\mu \mathrm{m})$ & 5 & $-10,0,10,20,30$ \\
Type of shaft supports & 1 & $\mathrm{BS}$ \\
\hline Total number of cases & 90 & \\
\hline
\end{tabular}

Table 6: Size of the finite element models

\begin{tabular}{lccc}
\hline Type of shaft support & FS & SS & BS \\
\hline Number of nodes of the smallest FE model & 470,190 & 470,190 & 591,150 \\
Number of elements of the smallest FE model & 508,317 & 508,314 & 665,588 \\
\hline Number of nodes of the largest FE model & 527,688 & 527,688 & 648,648 \\
Number of elements of the largest FE model & 565,971 & 565,971 & 723,242 \\
\hline
\end{tabular}

of this work are valid within this scope, but some of them are general and could be extrapolated.

Considering all cases in both sets, table 6 shows the number of nodes and elements of the smallest and largest FEM models. Through this table, it is possible to observe the important size of each one of the 261 FEM models solved and analyzed in this work, especially of those with bearing supports.

\section{Results and discussion}

For each one of the resulting cases of study, a finite element model has been developed following the ideas described before and, then, analyzed using Simulia Abaqus software. As a result, the misalignment of the pinion with respect to the rack has been computed measuring the displacements of the nodes placed on the keypoints, as explained in section 3 .

As it was described by Houser [17], when there is only one cylindrical gear mounted on the shaft, the elastic deflections of bearings and shaft are mostly produced in the direction of the plane of action $(\pi)$. Certainly, in this work, it has been verified through the results of the different cases of 
(a) $d_{s h}=20 \mathrm{~mm}$

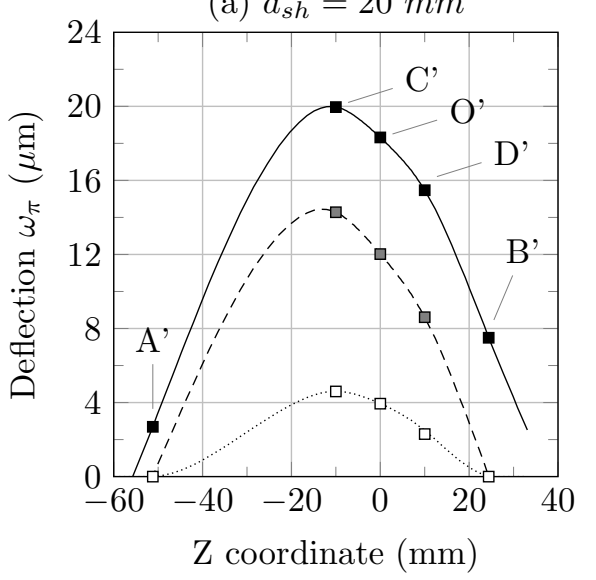

(b) $d_{s h}=28 \mathrm{~mm}$

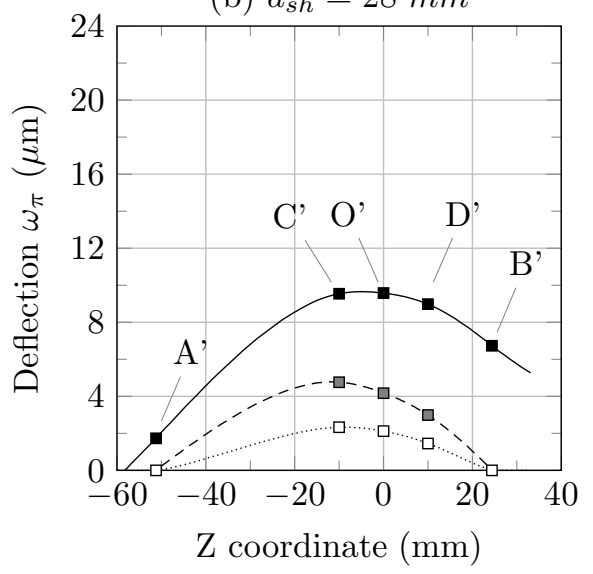

\begin{tabular}{lll|}
\hline BS- $-\quad$ SS- -- & FS $\cdots, \cdot]$ \\
\hline
\end{tabular}

Figure 7: Shaft deflection in the plane of action for two representative cases of study where the mounting position of the pinion is $z_{g}=0.7 \mathrm{~L}$, the applied torque is $T=75 \mathrm{Nm}$ and the axial interference is $\delta_{a}=0 \mu \mathrm{m}$

study that the deflections in the plane $\gamma$ are negligible compared to those in plane $\pi$. For this reason, the following studies are centered in the magnitudes of misalignment related to plane $\pi$ and no special attention is paid to the magnitudes in plane $\gamma$.

Figure 7 shows the pinion shaft deflection in the plane of action $\left(\omega_{\pi}\right)$ for two representative cases of study (corresponding to shaft diameters of 20 and $28 \mathrm{~mm}$ ) with the three types of shaft supports. It can be observed that the highest deflection values are obtained with the bearing supported model, followed by the simply supported model and, finally, the fully supported model. This result is expectable and it is also observed in the rest of cases of study.

Furthermore, considering all solved cases, some similar tendencies of shaft deflection are observed between the simply supported cases and the bearing supported cases. On the contrary, the shaft deflection in fully supported cases is not considered realistic and has no similarities with the deflection with other types of supports. For this reason and for the aim of brevity, the fully supported shaft will not be included in the following analyses. 


\subsection{Study of the influence of the applied torque on the misalignment of the pinion}

When the power is transmitted through the pinion and rack transmission, a pressure distribution is generated in the contact area between the gear teeth. This contact pressure distribution produces the deflection of the elastic elements of the transmission, causing the misalignment of both gears. As the applied torque becomes higher, the contact pressure is also higher, and it produces larger deflections that may increase the misalignment. This is the reason why a direct relation between the applied torque and the magnitudes of misalignment is expected.

But, in addition, a change in the misalignment of the gears involves a change in the contact area and, consequently, in the contact pressure distribution. This affects the deflection of the elastic elements of the transmission, modifying the misalignment and leading to a coupled non-linear problem. This problem has been solved by the finite element method for all cases of set $\mathrm{A}$ and figure 8 shows the resulting parameters of misalignment versus the torque for a few representative cases. The main conclusion that can be obtained is that, in all solved cases, the relation between the parameters of misalignment and the torque is very close to be linear. The reason is that the deflections produced by the transmitted torque are relatively small, so the non-linearity of the problem with respect to variations of the transmitted torque is also small. And this conclusion is reasonable for most commercial transmissions since their parts are designed to have a high stiffness.

Comparing the simple supported cases (SS) with the bearing supported cases (BS) it can be observed that, while in the first cases the non-linearity is practically inexistent, in the second cases this non-linearity increases slightly. But, in all cases, the relation between the parameters of misalignment and the torque could be considered linear (within the scope of this study) with a very high level of accuracy.

The linear relation that was revealed in this study implies that, in the following studies, the same conclusions could be obtained with any value of torque within the scope of this work. For this reason, in the following sections, the result from the different studies will be presented with the intermediate value of the torque $(75 \mathrm{Nm})$ without losing generality.

Regarding the axial displacement of the pinion, in spur gears there is not theoretical axial load and the induced axial load due to shaft deflection is negligible for small deformations. As a result, in all simple supported cases (SS) the obtained axial displacement is practically zero. But in bearing 


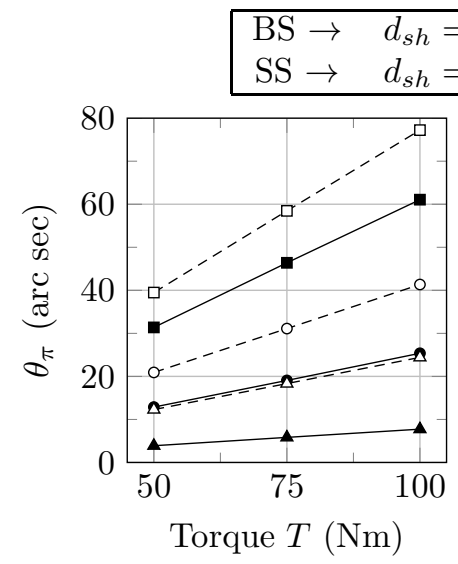

(a)

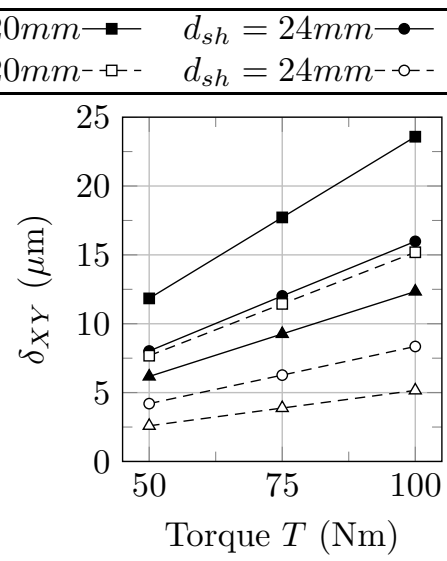

(b)

$$
\begin{aligned}
& d_{s h}=28 m m- \\
& d_{s h}=28 m m^{---}
\end{aligned}
$$

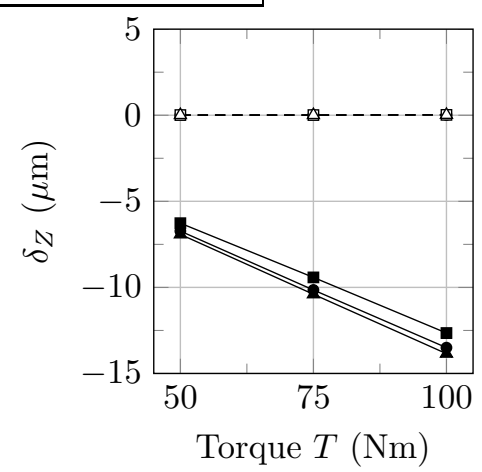

(c)

Figure 8: Evolution of the misalignment of the pinion for a selection of representative cases where $z_{g}=0.7 L$ : (a) angular misalignments parallel to the plane of action, (b) transversal displacement and (c) axial displacement of the pinion.

supported cases (BS), the radial load of the bearings induces a thrust load that may displace the pinion depending on its position over the shaft, as it can be observed in figure $8 \mathrm{c}$. This phenomenon is described with more detail in the following section.

\subsection{Study of the influence of the pinion shaft diameter and pinion mounting position on the misalignment of the pinion}

In a gear transmission, one of the main contributions to the misalignment of the gears is the deflection of the shafts. The amount of deflection of a shaft under load depends on its stiffness, on the type and position of its supports and on the position and magnitude of the applied loads. The stiffness of a shaft is related to its length, diameter and material and the magnitude and position of the applied loads (contact forces) depend on the mounting position of the pinion over the shaft and on the magnitude of the applied torque.

In this section, the variation of the misalignment of the pinion with these parameters is analyzed from the results of the FEM models corresponding to the set of cases A (table 4). Figure 9 shows the obtained angular misalignment in the plane of action $\left(\theta_{\pi}\right)$ for the intermediate value of torque, and for a selection of representative cases of study with both bearing supports 


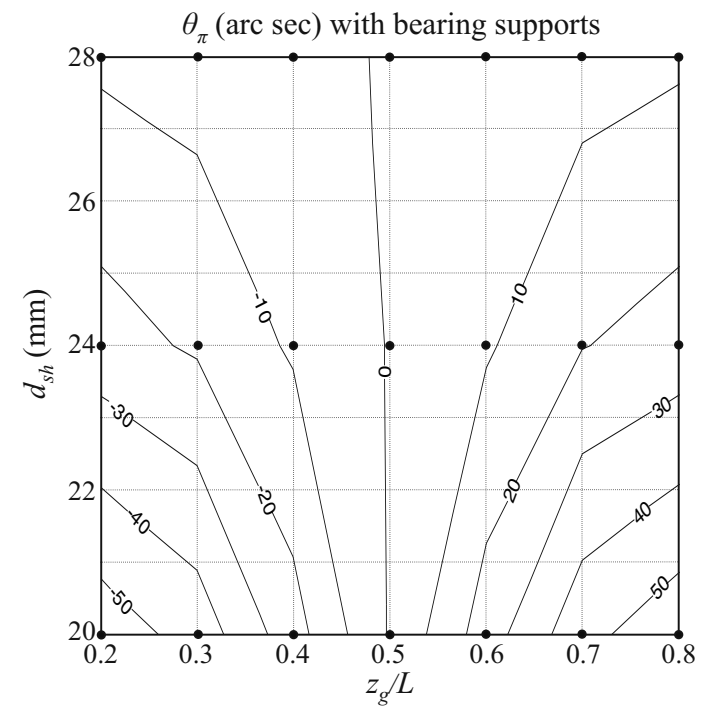

(a)

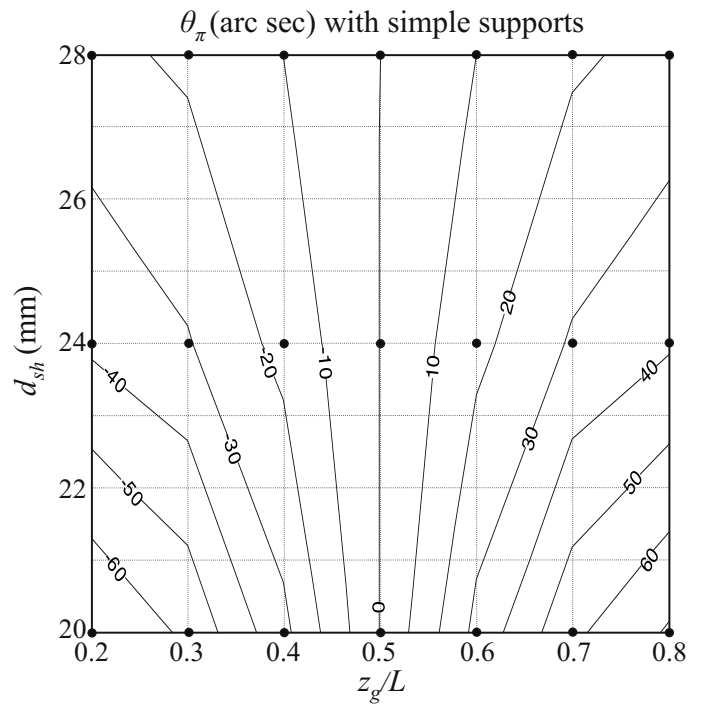

(b)

Figure 9: Evolution of angular misalignments parallel to the line of action with the shaft diameter $\left(d_{s h}\right)$ and mounting position $\left(z_{g} / L\right)$ when the applied torque is $75 \mathrm{Nm}$.

(figure 9a) and simple supports (figure 9b). In these figures, the small points represent the solved cases and the curves are interpolated from them.

It can be observed that, in both cases, the angular misalingment tends to zero when the pinion is in the midpoint of the bearing span $\left(z_{g} / L=0.5\right)$ and its absolute value increases as the pinion moves far away from this position, agreeing with what it was expected.

Furthermore, in both cases (BS and SS), when the pinion is mounted in a position that does not coincide with the midpoint of the bearing span, the angular misalignment is increased as the shaft diameter decreases. This is expectable because the slope of the deformed shaft increases when its stiffness decreases.

In all cases of set $A$, the angular misalignment obtained with bearing supports (BS) is lower than the angular misalignment obtained with simple supported shaft (SS). This is because the component of angular misalignment induced by the deflection of the bearings tends to compensate the angular misalignment produced by the shaft deflection, as it was explained in section 3.

On the other hand, figure 10 shows the results of transversal displacement 


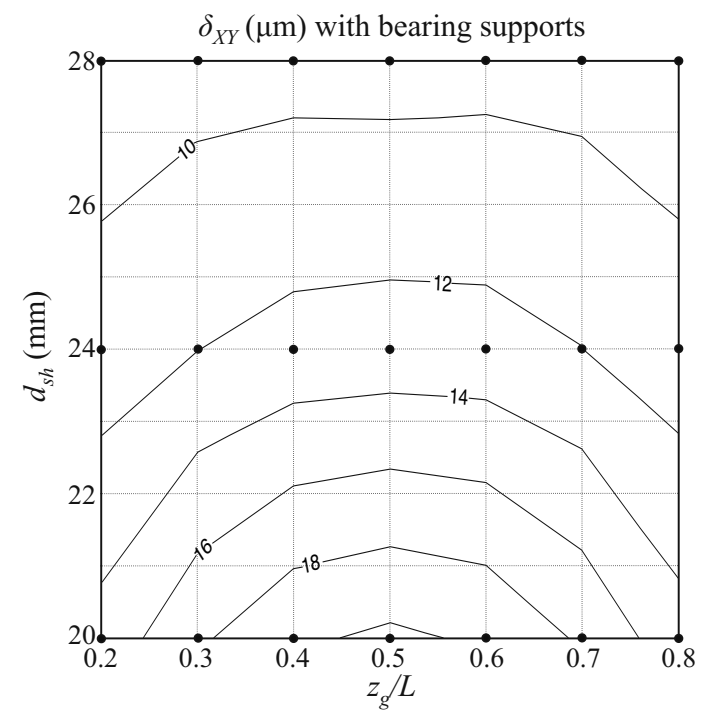

(a)

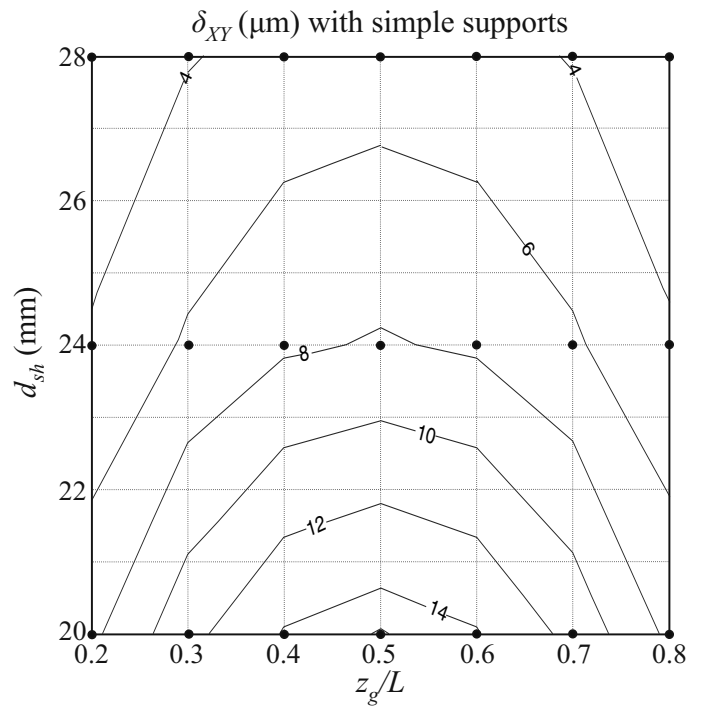

(b)

Figure 10: Evolution of the transversal displacement of the pinion with the shaft diameter $\left(d_{s h}\right)$ and mounting position $\left(z_{g} / L\right)$ when the applied torque is $75 \mathrm{Nm}$.

of the pinion $\left(\delta_{X Y}\right)$ obtained for the same cases of study with bearing supports (BS, figure 10a) and with simple supports (SS, figure 10b). It can be observed that in both cases the transversal displacement of the pinion is increased as the shaft diameter decreases because the stiffness of the shaft also decreases.

Besides that, the transversal displacement of the pinion is maximum when it is mounted at the midpoint of the bearing span because the deflection of the shaft decreases as the load is applied in a position closer to the supports.

And, finally, in all cases, the transversal displacement of the pinion is higher with bearing supports than with simple supports since the transversal displacement of the pinion produced by the deflection of bearings and the transversal displacement produced by the shaft deflection always sum up, as stated in section 3 .

The axial displacement of the pinion has been also obtained for all cases. In cases with simple supports (SS) this axial displacement is practically zero as it was justified in section 6.1. But, in cases with bearings (BS), this axial displacement is not null as it is observed figure 11. It can be seen that the axial displacement tends to increase as the pinion is moved away from the midpoint of the bearing span. The reason is that, in tapered roller bearings, 


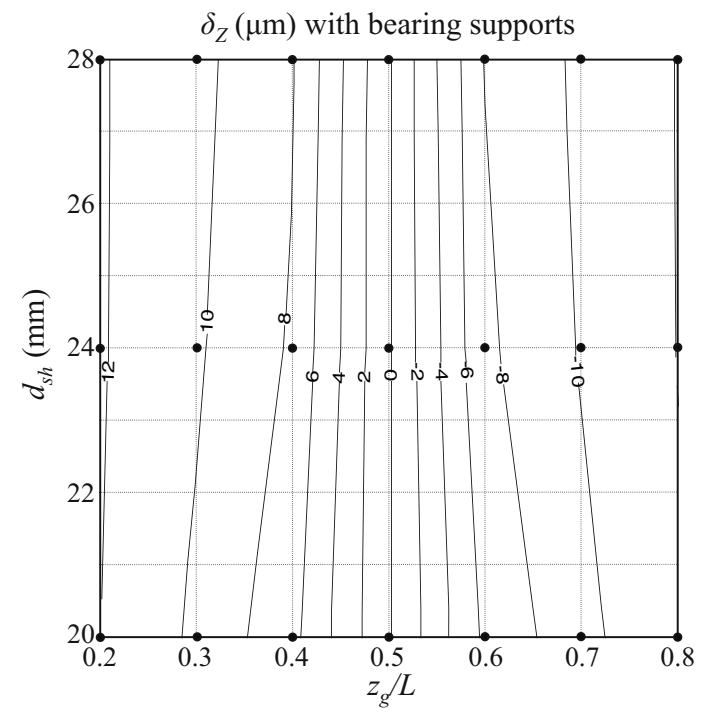

Figure 11: Evolution of the axial displacement of the pinion with the shaft diameter and mounting position when the applied torque is $75 \mathrm{Nm}$.

the radial load induces a thrust reaction within the bearing because of the taper, that tends to push the shaft towards the other bearing. Since the tapered roller bearing that is closer to the pinion supports more radial load than the other one, it creates a larger thrust load, that produces the axial displacement of the pinion. This displacement is the result of the compression of the shaft plus the deflection of the compressed bearing in the axial direction. Since a higher diameter of the shaft implies a higher stiffness in both shaft and bearings, the axial displacement of the pinion decreases when the diameter increases.

\subsection{Study of the contribution of the deflection of the bearings to the mis- alignment of the pinion}

To evaluate the contribution of the deflection of the bearings to the angular misalignment of the pinion, the ratio $R_{\pi}^{(\theta)}$, defined as the relation between the angular misalignment produced by the deflection of the shaft $\left(\theta_{\pi s}\right)$ and the angular misalignment produced by the deflection of the bearings $\left(\theta_{\pi b}\right)$, has been analyzed. From the definition of this ratio, several theoretical ranges with different meaning can be defined, as shown in figure 12. It is easy to observe that the optimum value of $R_{\pi}^{(\theta)}$ is -1 , since this value means that the angular misalignment produced by the deflection of the bearings com- 


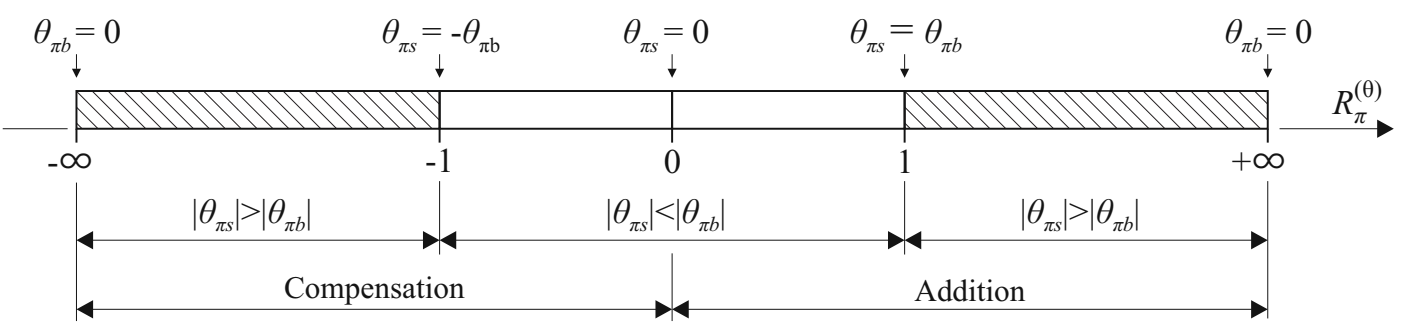

Figure 12: Theoretical ranges for the ratio $R_{\pi}^{(\theta)}$.

pletely compensates the angular misalignment produced by the deflection of the shaft, resulting a zero angular misalignment of the pinion with respect to the rack.

The ratio $R_{\pi}^{(\theta)}$ has been computed from the results of the FEM models corresponding to the set of cases $\mathrm{A}$ and figure 13a shows the ratio for the cases where the applied torque is $75 \mathrm{Nm}$. In that figure, the region where $R_{\pi}^{(\theta)}<0$ corresponds to designs where the angular misalignment produced by the shaft deflection is partially compensated by the angular misalignment produced by the deflection of the bearings $\left(\theta_{\pi s}\right.$ and $\theta_{\pi b}$ have different sign). On the other hand, the hatched region corresponds to designs where the absolute angular misalignment produced by the shaft deflection is higher than the absolute angular misalignment produced by the deflection of the bearings $\left(\left|\theta_{\pi s}\right|>\left|\theta_{\pi b}\right|\right)$.

It is important to remark that, in figure 13a there is a central region (in gray) where the angular misalignments $\theta_{\pi s}$ and $\theta_{\pi b}$ are both close to zero and the numerical errors associated to the FEM model introduce uncertainty to the value of $R_{\pi}^{(\theta)}$. Consequently, the only conclusion that can be extracted in this region is that the total angular misalignment is practically zero.

Besides that, in most part of the design space of figure 13a (region where $R_{\pi}^{(\theta)}<0$ ) the angular misalignments due to shaft deflection and bearing deflections have different sign and partially compensate each other.

On the other hand, the study revealed that the contribution of the shaft deflection to the angular misalignment of the pinion is more important than the contribution of the deflection of the bearings in most part of the design space (hatched region). This difference depends on the relative stiffness of both elements and, to evaluate the contribution of the deflection of the bearings, the relative error of the obtained angular misalignment associated to not including the roller bearings in the FEM model has been computed 


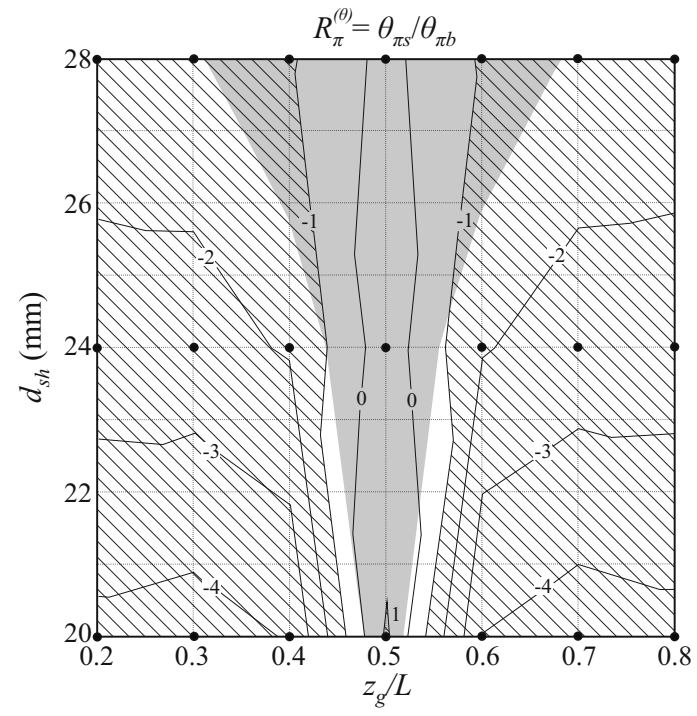

(a)

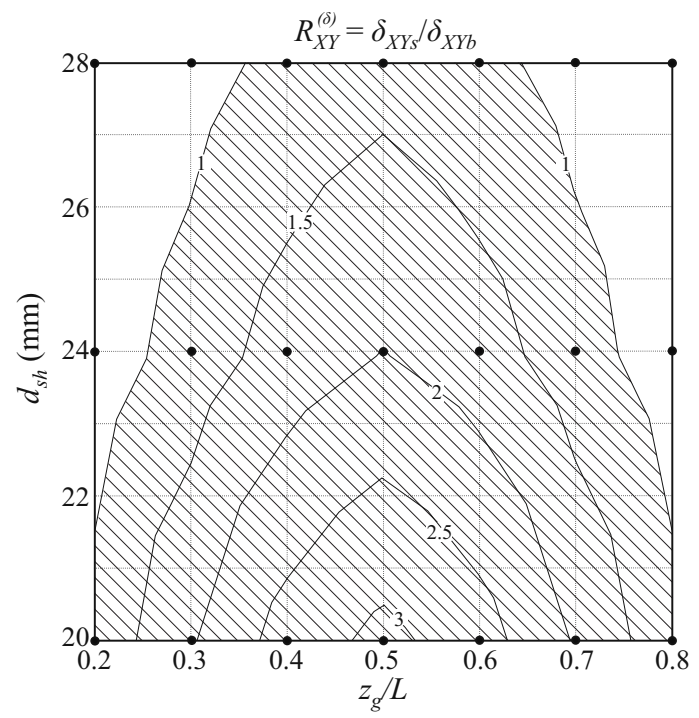

(b)

Figure 13: Relation of misalignments induced by the deflection of shaft and bearings.

(figure 14a). This error $\varepsilon_{\pi}^{(\theta)}$ is defined as the absolute value of angular misalignment due to the deflection of the bearings divided by the absolute total angular misalignment considering the deflections of both shaft and bearings. Once again, no conclusions should be extracted from the central region (in gray) for the reason explained above. But out of this area it is possible to observe that not considering the bearings implies a relative error from $25 \%$ up to a very high value in the estimation of the angular misalignment of the pinion. And, as expected, this error increases when the stiffness of the shaft relative to the stiffness of the bearings also increases.

A similar analysis has been performed with the transversal displacement of the pinion. A ratio $R_{X Y}^{(\delta)}$ has been defined as the quotient between the transversal displacement due to shaft deflection $\left(\delta_{X Y s}\right)$ and the transversal displacement due to the deflection of the bearings $\left(\delta_{X Y b}\right)$. The results obtained for this ratio are presented in figure $13 \mathrm{~b}$ for the cases where the applied torque is $75 \mathrm{Nm}$. In this case, both displacements always sum up (they never compensate each other) and the results show that in most part of the design space (hatched region where $R_{X Y}^{(\delta)}>1$ ) the displacement due to shaft deflection is higher than the displacement due to the deflection of the bearings. When $R_{X Y}^{(\delta)}=1$, both displacements $\delta_{X Y s}$ and $\delta_{X Y b}$ are equal and this curve 


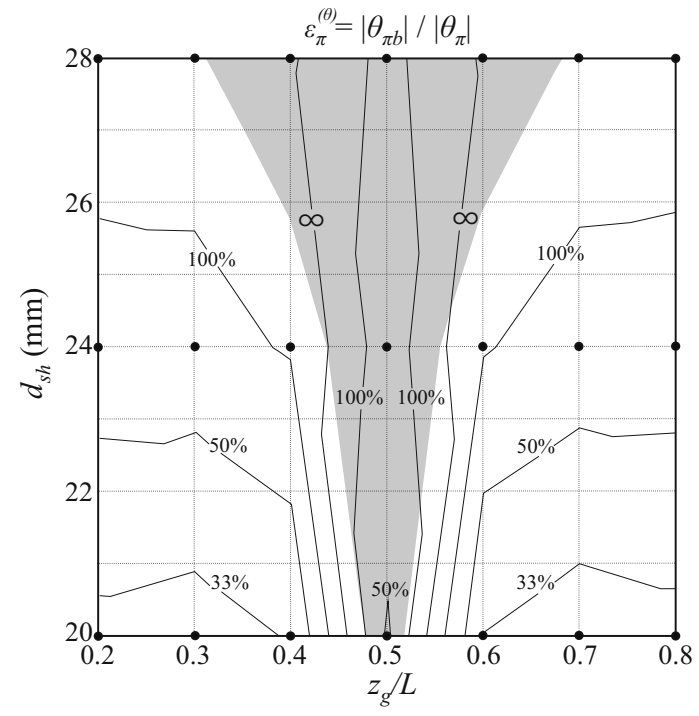

(a)

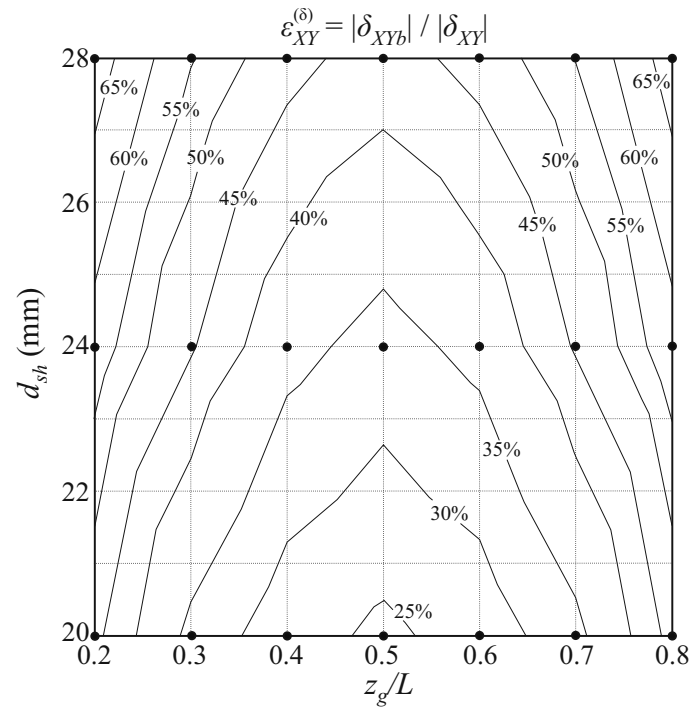

(b)

Figure 14: Relative misalignment error associated to not considering the bearings.

is the frontier where the relative importance of the deflection produced by shaft and bearings changes. The displacement produced by the deflection of the bearings $\left(\delta_{X Y b}\right)$ becomes more important when the stiffness of the shaft increases and when the mounting position of the pinion is closer to the supports (bearings). The displacement produced by the shaft deflection increases just the opposite. The frontier of relative importance $\left(R_{X Y}^{(\delta)}=1\right)$ depends on the relative stiffness of shaft and bearings.

Finally, to illustrate the importance of considering the bearings when evaluating the transversal displacement of the pinion, the contribution of the bearings is presented in figure $14 \mathrm{~b}$ as the relative error of not considering the bearings $\left(\varepsilon_{X Y}^{(\delta)}\right)$. It can be observed that this error is always higher than $25 \%$ and it reaches values around $65 \%$ as the shaft is relatively stiffer than the bearings and as the pinion is closer to one of the bearings.

6.4. Study of the linearity of the problem of computing the transversal displacement of the pinion

In some gear design guides [1], it is a common practice to determine the transversal displacement produced by the deflection of the roller bearings $\left(\delta_{X Y b}\right)$ (considering a linear model of displacement between the bearings) and 


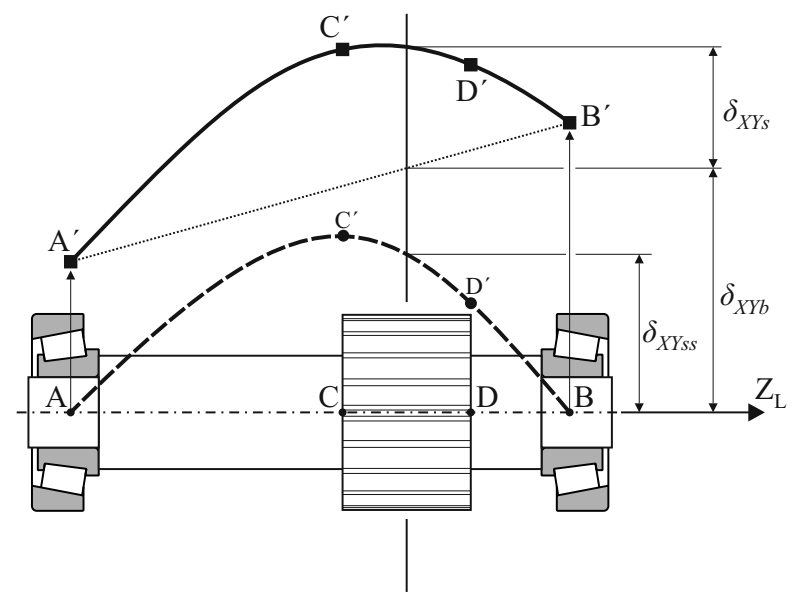

(a)

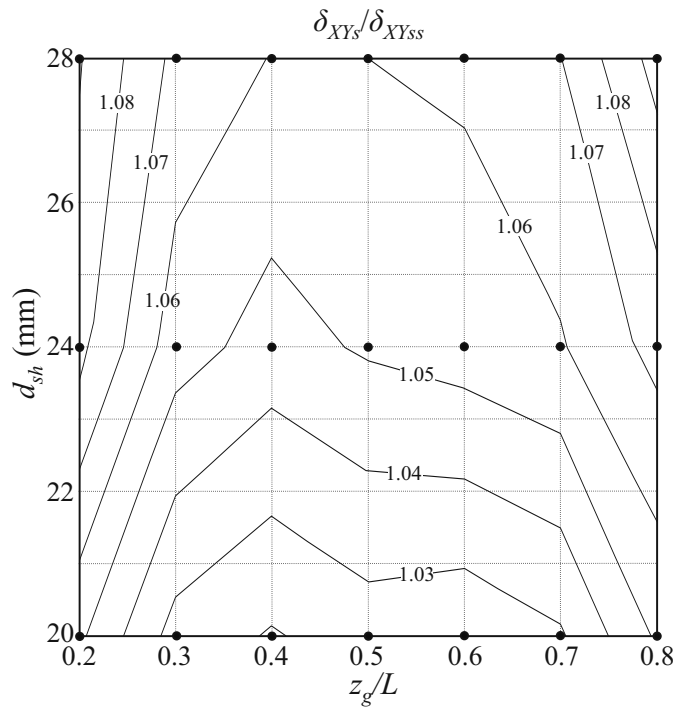

(b)

Figure 15: Ratio of transversal displacements due to shaft deflection with bearings and without bearings.

the transversal displacement produced by the deflection of a simply supported shaft $\left(\delta_{X Y s s}\right)$ separately, and then apply the principle of superposition to determine the total misalignment of the transmission. However, as it has been mentioned in section 3, both parameters are coupled to a certain degree, and subsequently, applying the principle of superposition can lead to imprecisions in the results.

To quantify the linearity of the problem in the transmission used in this work, the component of transversal displacement of the pinion produced by the flexibility of the shafts $\left(\delta_{X Y s}\right)$ is compared to the transversal displacement of the pinion in a simply supported case $\left(\delta_{X Y s s}\right)$, as shown in figure $15 \mathrm{a}$. The results of this comparison for those combinations of the set of cases A (table 4) where the applied torque is $75 \mathrm{Nm}$ are shown in figure $15 \mathrm{~b}$.

It can be observed that the ratio $\delta_{X Y s} / \delta_{X Y s s}$ is always greater than 1 , what means that the transversal displacement of the pinion obtained by a model including both pinion and bearings is always higher than the one obtained by computing separately the deflection of the pinion and the deflection of the bearings. But, the values in figure $15 \mathrm{~b}$ are very close to 1 , what means that the error assumed by applying the principle of superposition is small 
(lower than 9\% in the scope of this study). This error increases when the diameter of the shaft also increases or when the pinion is moved away from the midpoint of the bearing span.

The slight lack of symmetry of the obtained results is produced by numerical errors in the FEM models and also by the torque, that is the only element breaking the symmetry of the models.

\subsection{Study of the influence of the axial interference on the misalignment of the pinion}

The application of an axial interference on tapered roller bearings of gear transmissions is a common practice in the industry that can help to improve the rigidity, guiding accuracy and smoothness of the operation [27]. In consequence, it may have some effect on the misalignment of the gears [28] that is investigated in this section. Thus, the influence of the interference on the misalignment of the pinion is analyzed considering the set of cases B (table 5). The computation of the FEM models provided results that are analyzed separately for both positions of the pinion. When $z_{g} / L=0.7$, the resulting parameters of misalignment versus the interference on the bearings are presented in figure 16 for different shaft diameters and the intermediate torque $(T=75 \mathrm{Nm})$. On the other hand, in figure 17 the information is presented for different torques and the intermediate shaft diameter $\left(d_{s h}=24 \mathrm{~mm}\right)$.

By observing figures 16 and 17 it can be said that all misalignment parameters have a monotonic variation with the axial interference on bearings, for all considered shaft diameters and torques. The angular misalignment $\left(\theta_{\pi}\right)$ and the axial displacement $\left(\delta_{Z}\right)$ of the pinion have a monotonic increase with the axial interference while the transversal displacement of the pinion $\left(\delta_{X Y}\right)$ has a monotonic decrease with the interference. Furthermore, it can be observed that all parameters converge to an extreme value when the interference is increased, being this extreme value different for different shaft diameters and torques. But while the rate of convergence is practically independent from the shaft diameter (figure 16), it demonstrates to be dependent from the torque (figure 17), being the convergence faster for low torques.

When the pinion is centered in the bearing span $\left(z_{g} / L=0.5\right)$, the obtained angular misalignment and axial displacement of the pinion are both negligible compared to the results when $z_{g} / L=0.7$. However, the transversal displacement is of the same order of magnitude as the transversal displacement when $z_{g} / L=0.7$ and follows the same tendencies, so similar conclusions can be obtained. 


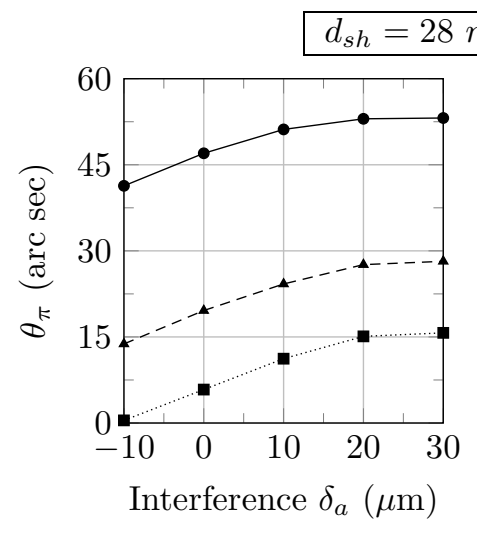

(a)

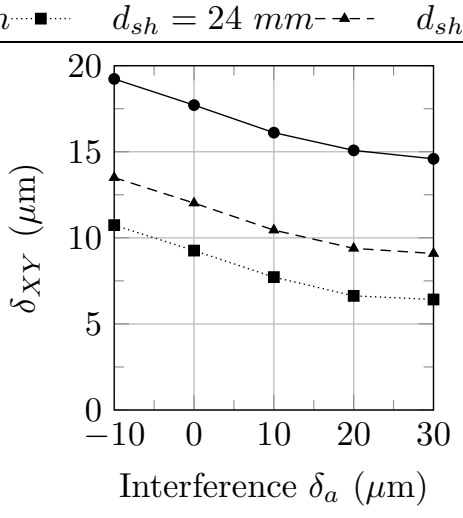

(b)

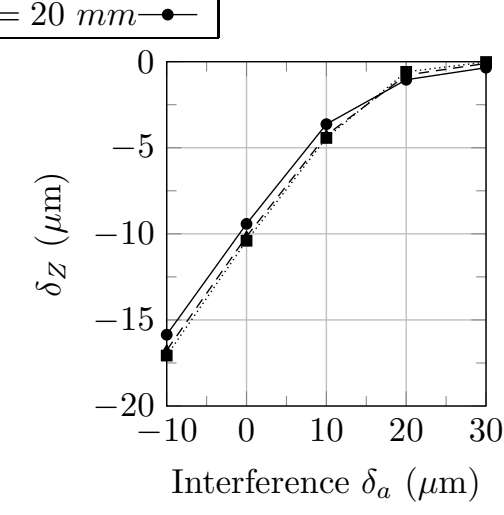

(c)

Figure 16: Evolution of the misalignment of the pinion with the axial interference and shaft diameter for cases of study where $T=75 \mathrm{Nm}$ and $z_{g} / L=0.7$ : (a) angular misalignments parallel to the plane of action, (b) transversal displacement and (c) axial displacement of the pinion.

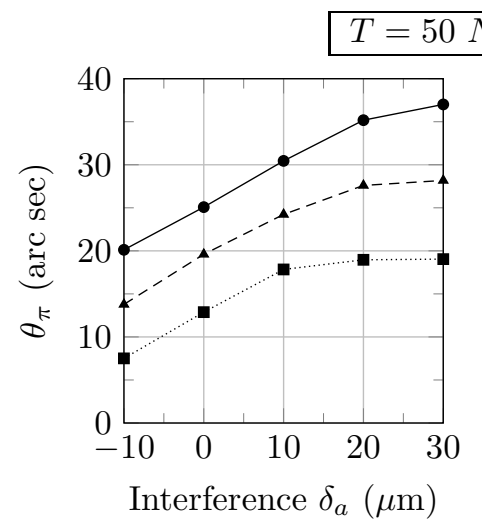

(a)

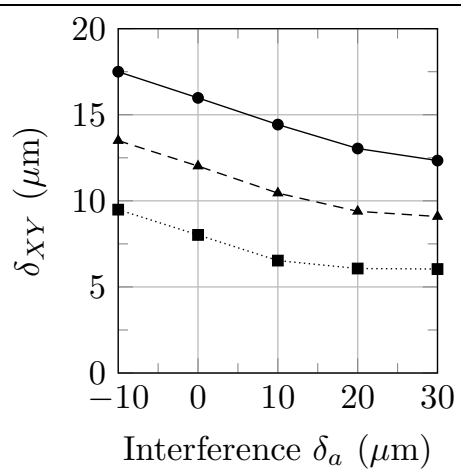

(b)

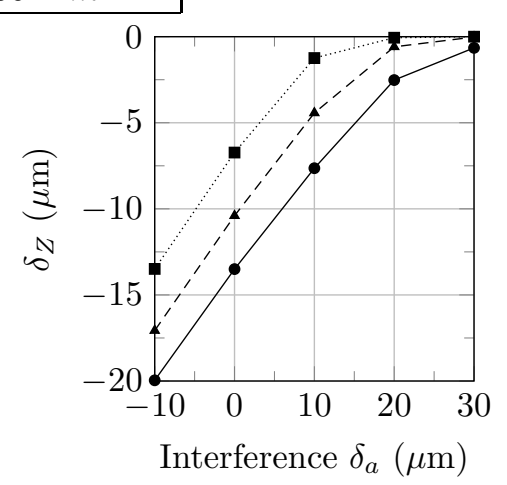

(c)

Figure 17: Evolution of the misalignment of the pinion with the axial interference and applied torque for cases of study where $d_{s h}=24 \mathrm{~mm}$ and $z_{g} / L=0.7$ : (a) angular misalignments parallel to the plane of action, (b) transversal displacement and (c) axial displacement of the pinion. 


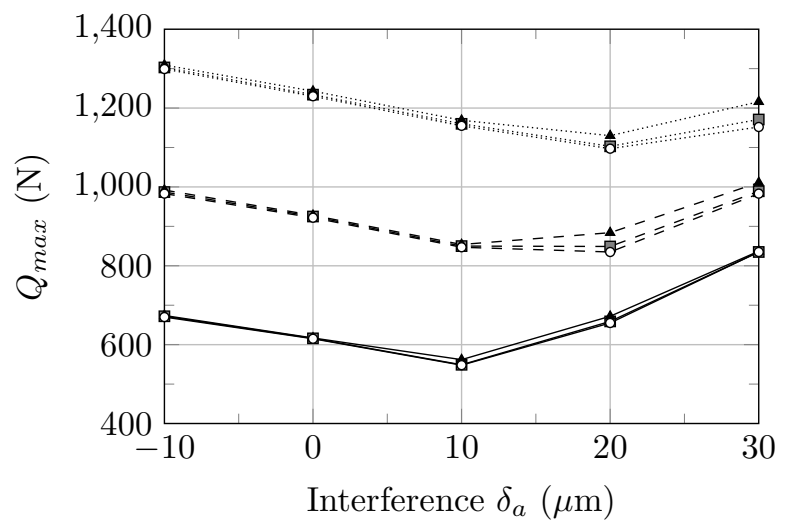

\begin{tabular}{|c|c|c|c|c|}
\hline$d_{s h}=28 \mathrm{~mm}$ & & $T=50 N m \multimap$ & $T=75 N m^{-॰-}$ & $T=100 N m \cdots \circ \cdots$ \\
\hline$d_{s h}=24 \mathrm{~mm}$ & $\rightarrow$ & $T=50 \mathrm{Nm} \longrightarrow$ & $T=75 \mathrm{Nm}-\square-$ & $T=100 N m \cdots \square \cdots$ \\
\hline$d_{s h}=20 \mathrm{~mm}$ & $\rightarrow$ & $T=50 N m \smile$ & $T=75 \mathrm{Nm}^{-\wedge}$ & $T=100 N m$ \\
\hline
\end{tabular}

Figure 18: Evolution of the maximum load in the rolling elements of bearings with the axial interference

In addition to the effect on the misalignment, the introduction of a slight preload to the bearings can help to maximize their life [28], but if the preload is excessive the opposite effect could be obtained [29], arriving at a drastic reduction of the fatigue life of bearings.

According to Harris [22], the life of bearings is related to the maximum total load $\left(Q_{\max }\right)$ supported by one roller. This maximum total load has been computed from the results of the FEM models corresponding to cases in set B and figure 18 shows the evolution of this parameter (maximum load supported by a rolling element) versus the imposed axial interference. It can be observed that the maximum load in the rollers practically does not change with the shaft diameter but it does significantly with the applied torque, as expected. In addition, there is an optimum value of interference where the maximum load supported by the roller is minimum. And this optimum value increases with the torque.

\section{Conclusions}

In this work, the contribution of the flexibility of roller bearings to the misalignment of the pinion in a pinion-rack transmission has been analyzed. The work is based on a typical commercial design of this type of transmissions where different design parameters have been varied to obtain 261 design cases. 
A realistic 3D FEM model has been built for each one of these cases and the coupled structural and contact problem has been solved. From the results of the FEM models, the parameters of misalignment of the pinion have been obtained and five studies have been performed to evaluate the influence of the roller bearings in that misalignment.

As a result of these studies, the following conclusions have been obtained:

- The relationship between all parameters of the misalignment (angular misalignment, transversal displacement and axial displacement) and the transmitted torque is practically linear in both types of models (with simple supported shaft and with bearing supported shaft) because of the high stiffness of the elements of the transmission.

- The consideration of bearing supports reduce the angular misalignment because the deflection of the bearings partially compensate the angular misalignment produced by the deflection of the shaft. In other words, not including the bearings in a model of the transmission produces an overestimation of the angular misalignment of the pinion.

- The consideration of bearing supports increase the transversal displacement of the pinion because of the radial deflection of the bearings. Thus, not including the bearings in a model of the transmission produces a underestimation of the transversal displacement of the pinion.

- The axial displacement of the pinion is practically zero with the simple supported shaft, but it is not zero with tapered roller bearing as supports because of the axial load induced by the radial load in the bearings. This displacement increases as the mounting position of the pinion over the shaft gets away from the midpoint of the bearing span.

- The relative importance of the contribution of the shaft deflection and the contribution of the deflection of the bearings to the angular misalignment of the pinion depends on the relative stiffness of shaft and bearings. In the scope of this work, if the stiffness of the shaft is relatively higher, the relative error associated to not considering the bearings can be higher than $100 \%$. On the other hand, if the stiffness of the shaft is relatively lower, the relative error can be lower than $33 \%$. But, in any case, the studies demonstrated the high importance of including the bearings when computing the angular misalignment of the pinion. 
- Similarly, the contribution of the shaft deflection to the transversal displacement of the pinion can be more important than the contribution of the deflection of the bearings. But this importance decreases as the pinion gets closer to the supports and as the stiffness of the shaft relative to the stiffness of the bearings increases.

- The determination of the total transversal displacement of the pinion by computing separately the displacement produced by the deflection of the roller bearings and the displacement produced by the deflection of a simply supported shaft and, then, by applying the principle of superposition is a common practice. The studies demonstrated that, within the scope of this work, this practice implies a low error because the small deflections of the structural elements reduces the non-linearity of the coupled structural and contact problem.

- It is known that the application of an axial interference on the tapered roller bearings of a gear transmission can help to improve the rigidity, guiding accuracy and smoothness of the operation. But, in addition, the analysis in this work demonstrated that this practice has influence on the misalignment of the pinion. Thus, while the angular misalignment and axial displacement of the pinion increases with the imposed interference, the transversal displacement decreases. In

all cases, the parameters converged to an extreme value when the interference is increased and the rate of convergence is higher for high torques. Furthermore, it has been verified that there is an optimum value of interference that minimizes the maximum total load supported by the rollers, maximizing the life of the bearings, and this optimum value increases with the torque.

In summary, this work demonstrated that the deformation of the tapered roller bearings associated to the pinion shaft has an important influence on different aspects related to the misalignment of the pinion in a pinion-rack transmission. Not considering the bearings in the contact and structural problem may lead to important errors in the estimation of the position of the pinion under load.

\section{Acknowledgements}

The authors express their deep gratitude to the Spanish Ministry of Science and Innovation (MICINN) for the financial support of research project 
ref. DPI2013-47702-C2-2-P.

\section{References}

[1] ISO 6336-1, Calculation of load capacity of spur and helical gears, Tech. rep., International Organization for Standardization, Geneva, Switzerland (2006).

[2] ANSI/AGMA 2001-D04, Fundamental rating factors and calculation methods for involute spur and helical gear teeth, Tech. rep., American gear manufacturers association, Alexandria, USA (2004).

[3] J. Haigh, J. Fawcett, Effects of misalignment on load distribution in large face-width helical gears, Proceedings of the Institution of Mechanical Engineers, Part K: Journal of Multi-body Dynamics 217 (2) (2003) 9398.

[4] V. Roda-Casanova, F. Sanchez-Marin, I. Gonzalez-Perez, J. Iserte, A. Fuentes, Determination of the ISO face load factor in spur gear drives by the finite element modeling of gears and shafts, Mechanism and Machine Theory 65 (2013) 1-13.

[5] M. Hotait, A. Kahraman, Experiments on root stresses of helical gears with lead crown and misalignments, Journal of Mechanical Design, Transactions of the ASME 130 (7) (2008) 0745021-0745025.

[6] S. Li, Finite element analyses for contact strength and bending strength of a pair of spur gears with machining errors, assembly errors and tooth modifications, Mechanism and Machine Theory 42 (1) (2007) 88-114.

[7] S. Li, An investigation on the influence of misalignment on micro-pitting of a spur gear pair, Tribology Letters 60 (3).

[8] M. Pau, B. Leban, A. Baldi, F. Ginesu, Experimental contact pattern analysis for a gear-rack system, Meccanica 47 (1) (2012) 51-61.

[9] S. Barone, L. Borgianni, P. Forte, Evaluation of the effect of misalignment and profile modification in face gear drive by a finite element meshing simulation, Journal of Mechanical Design, Transactions of the ASME 126 (5) (2004) 916-924. 
[10] C. Das, S. Albert, A. Bhaduri, S. Ray, Failure analysis of a pinion, Engineering Failure Analysis 12 (2) (2005) 287-298.

[11] K. Mao, Gear tooth contact analysis and its application in the reduction of fatigue wear, Wear 262 (5-6) (2007) 505-513.

[12] T. Osman, P. Velex, Static and dynamic simulations of mild abrasive wear in wide-faced solid spur and helical gears, Mechanism and Machine Theory 45 (6) (2010) 911-924.

[13] J. Zhang, X. Liu, Effects of misalignment on surface wear of spur gears, Proceedings of the Institution of Mechanical Engineers, Part J: Journal of Engineering Tribology 229 (9) (2015) 1145-1158.

[14] J. Smith, Helical gear vibration excitation with misalignment, Proceedings of the Institution of Mechanical Engineers, Part C: Journal of Mechanical Engineering Science 208 (2) (1994) 71-79.

[15] A. Palermo, D. Mundo, R. Hadjit, W. Desmet, Multibody element for spur and helical gear meshing based on detailed three-dimensional contact calculations, Mechanism and Machine Theory 62 (2013) 13-30.

[16] H. Jiang, Y. Shao, C. Mechefske, X. Chen, The influence of mesh misalignment on the dynamic characteristics of helical gears including sliding friction, Journal of Mechanical Science and Technology 29 (11) (2015) 4563-4573.

[17] D. Houser, J. Harianto, D. Talbot, Gear mesh misalignment, Gear solutions 6 (2006) 34-43.

[18] M. Hotait, A. Kahraman, T. Nishino, An investigation of root stresses of hypoid gears with misalignments, Journal of Mechanical Design, Transactions of the ASME 133 (7).

[19] T. Koide, S. Oda, S. Matsuura, A. Kubo, Equivalent misalignment of gears due to deformation of shafts, bearings and gears (model proposal and development of calculation program), JSME International Journal, Series C: Mechanical Systems, Machine Elements and Manufacturing 46 (4) (2003) 1563-1571. 
[20] J. Argyris, A. Fuentes, F. Litvin, Computerized integrated approach for design and stress analysis of spiral bevel gears, Computer Methods in Applied Mechanics and Engineering 191 (11-12) (2002) 1057-1095.

[21] ISO 355:2007, Rolling bearings tapered roller bearings boundary dimensions and series designations, Tech. rep., International Organization for Standardization, Geneva, Switzerland (2007).

[22] T. Harris, M. Kotzalas, Essential Concepts of Bearing Technology, Fifth Edition, CRC Press, 2006.

[23] J. Simo, M. Rifai, Class of mixed assumed strain methods and the method of incompatible modes, International Journal for Numerical Methods in Engineering 29 (8) (1990) 1595-1638.

[24] S.-Y. Ye, S.-J. Tsai, Loaded tooth contact analysis of power-split gear drives considering shaft deformation and assembly errors, in: Proceedings of the ASME Design Engineering Technical Conference, Vol. 10, 2015.

[25] Hibbitt, Karlsson, Sorensen, Abaqus Analysis User's Manual, no. 5 in ABAQUS/Standard User's Manual, Simulia, 2010.

[26] Y. Guo, R. Parker, Stiffness matrix calculation of rolling element bearings using a finite element/contact mechanics model, Mechanism and Machine Theory 51 (2012) 32-45.

[27] I. Bercea, D. Nlias, S. Cretu, Optimum initial axial compression due to preload in an arrangement of two tapered roller bearings part 1: Analysis, Proceedings of the Institution of Mechanical Engineers, Part J: Journal of Engineering Tribology 214 (2) (2000) 125-134.

[28] D. Snyder, Adjusting tapered bearings, Motion System Design 47 (10) (2005) 40-41.

[29] T. E. Springer, C. M. Corneliussen, Setting techniques for tapered roller bearings, Power transmission design 37 (6) (1995) 59-63. 